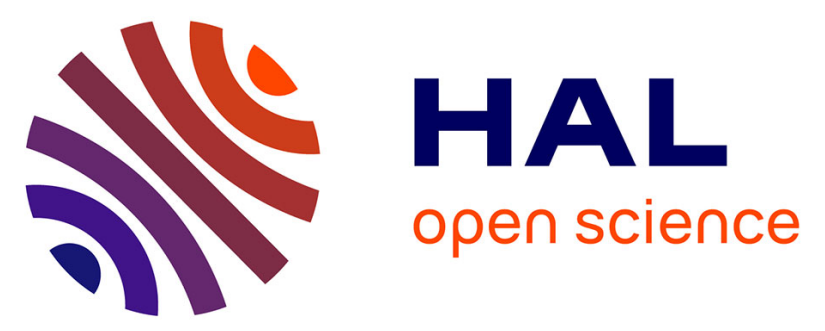

\title{
Mitochondrial translocator protein (TSPO) ligands prevent doxorubicin-induced mechanical dysfunction and cell death in isolated cardiomyocytes.
}

Alexandra d'Anglemont de Tassigny, Rana Assaly, Sophie Schaller, Rebecca M. Pruss, Alain Berdeaux, Didier Morin

\section{To cite this version:}

Alexandra d'Anglemont de Tassigny, Rana Assaly, Sophie Schaller, Rebecca M. Pruss, Alain Berdeaux, et al.. Mitochondrial translocator protein (TSPO) ligands prevent doxorubicin-induced mechanical dysfunction and cell death in isolated cardiomyocytes.. Mitochondrion, 2013, 13 (6), pp.688-97. 10.1016/j.mito.2013.10.001 . inserm-00920557

\section{HAL Id: inserm-00920557 https://www.hal.inserm.fr/inserm-00920557}

Submitted on 18 Dec 2013

HAL is a multi-disciplinary open access archive for the deposit and dissemination of scientific research documents, whether they are published or not. The documents may come from teaching and research institutions in France or abroad, or from public or private research centers.
L'archive ouverte pluridisciplinaire HAL, est destinée au dépôt et à la diffusion de documents scientifiques de niveau recherche, publiés ou non, émanant des établissements d'enseignement et de recherche français ou étrangers, des laboratoires publics ou privés. 


\section{Mitochondrial Translocator Protein (TSPO) ligands prevent}

\section{doxorubicin-induced mechanical dysfunction and cell death in isolated cardiomyocytes}

Alexandra d'Anglemont de Tassigny ${ }^{(1,2,4)}$, Rana Assaly ${ }^{(1,2)}$, Sophie Schaller ${ }^{(3)}$, Rebecca M. Pruss ${ }^{(3)}$, Alain Berdeaux ${ }^{(1,2)}$, Didier Morin ${ }^{(1,2)}$

(1) INSERM U955, équipe 3, Créteil, F-94010, France.

(2) Université Paris-Est, Faculté de Médecine, Créteil, F-94010, France.

(3) Trophos S.A., Parc Scientifique de Luminy, case 931, Marseille cedex 9, F-13288, France

(4) Institut Supérieur des BioSciences, Faculté de Médecine, Créteil, F-94010, France

Corresponding author : Didier MORIN, PHD

INSERM U955 - équipe 3

Faculté de Médecine de Créteil,

8, rue Général Sarrail

94010 CRETEIL Cedex

France

Tel : 33-1-49.81.36.51

Fax : 33-1-49.98.36.61

e-mail : didier.morin@inserm.fr 


\begin{abstract}
Contractile dysfunction and subsequent development of cardiomyopathies are well known limiting factors in the treatment of cancer with doxorubicin and have been linked to mitochondrial dysfunction. Here, using adult isolated paced cardiomyocytes, we have demonstrated that ligands of translocator protein (TSPO) 4'-chlorodiazepam and TRO40303 prevented the doxorubicin-induced alterations in contractility and improved cardiomyocyte viability. This cardioprotective effect was closely associated with both a potent reduction in reactive oxygen species production and inhibition of mitochondrial permeability transition pore opening. Thus, preventive administration of TSPO ligands may represent a novel pharmacological strategy to protect the heart during doxorubicin treatment.
\end{abstract}

Keywords: cardiomyocytes, doxorubicin, mitochondria, permeability transition pore, ROS, TSPO ligands.

Abbreviations: BAPTA, 1,2-bis(o-aminophenoxy)ethane-N,N,N',N'-tetraacetic acid ; $\mathrm{CoCl}_{2}$, cobalt chloride; CsA, cyclosporin A; DCF, dichlorofluorescein; DCFH-DA, 2,7dichlorodihydrofluorescein-diacetate ; CDZ, 4'-chlorodiazepam ; IMAC, inner membrane anion channel; mPTP, mitochondrial permeability transition pore ; $\mathrm{OH}$, hydroxyl radica 1; PI, propidium iodide ; ROS, reactive oxygen species ; TSPO, translocator protein 


\section{Introduction}

Doxorubicin, a quinone-containing anthracycline, is widely used as a chemotherapeutic agent for the treatment of a large spectrum of human neoplasic diseases. However, its administration in humans is limited by the risk of severe cardiotoxicity (Olson \& Mushlin, 1990; Singal \& Iliskovic, 1998; Minotti et al., 2004) including transient arrhythmias, nonspecific electrocardiographic abnormalities, pericarditis and transient depression of left ventricular function (Ferreira et al., 2008). A large part of these abnormalities results from an impaired contractility and subsequent development of cardiomyopathies secondary to alterations in cellular structure (Lim et al., 2004), cell death (Minotti et al., 2004; Childs et al., 2002; Keefe et al., 2001) with ceramide accumulation, mitochondrial dysfunction, cytochrome c release (Childs et al., 2002; Delpy et al., 1999; Kalyanaraman et al., 2002) and generation of reactive oxygen species (ROS) (Tsang et al., 2003).

Mitochondrial dysfunction has been identified as an important event in doxorubicininduced damage (Lebrecht et al., 2007; Montaigne et al., 2010) including loss of ATP synthesis, increased ATP hydrolysis, impairment of ionic homeostasis and ROS generation (Doroshow \& Davies, 1986; Sawyer et al., 1999; Timolati et al., 2006). Indeed, mitochondrial respiratory chain is a major source of ROS production during doxorubicin treatment through inhibition of respiratory complexes (Berthiaume \& Wallace, 2007; Tokarska-Schlattner et al., 2005). ROS production leads to the reduction in oxidative phosphorylation capacity and ultimately to an increase in the permeability of mitochondrial membranes through opening of the mitochondrial transition pore (mPTP), a multiprotein complex, leading to mitochondrial swelling and subsequent release of pro-apoptotic factors (Halestrap, 2009; Zoratti \& Szabo, 1995). 
In this context, any pharmacological strategy preventing mitochondrial dysfunction during doxorubicin treatment has therapeutic potential among which are the ligands of the translocator protein (TSPO) formerly named the peripheral benzodiazepine receptor. TSPO is a $18-\mathrm{kDa}$ protein located in the outer mitochondrial membrane and a putative component of the mPTP multiprotein complex (Gavish et al., 1999; Papadopoulos et al., 2006). TSPO is abundant in steroïdogenic tissues where it mediates the transport of cholesterol from the outer to the inner mitochondrial membranes (Papadopoulos et al., 1990). TSPO is also present in non-steroïdogenic tissues such as the heart where its function remains unknown. Recently, several studies have shown that TSPO ligands prevented apoptosis, reduced mitochondrial permeabilization and ultimately the incidence of arrhythmias as well as left ventricular dysfunction and infarct size following myocardial ischemia-reperfusion in rats (Obame et al., 2007; Schaller al., 2010; Xiao et al., 2010).

In this study, we investigated the possible preventive effect of TSPO ligands against doxorubicin-induced cardiotoxicity in isolated adult mouse and rat cardiomyocytes. Two structurally unrelated TSPO ligands were used, the benzodiazepine, 4'-chlorodiazepam, (Johnson et al., 1986 ) and the new ligand, TRO40303, that binds specifically to the cholesterol site of TSPO, which is different than the 4'-chlorodiazepam binding site (Schaller et al., 2010), on contractile performance and cell death of isolated adult cardiomyocytes treated with doxorubicin. 


\section{Materials and methods}

\subsection{Animals}

All animal procedures used in this study were in accordance with the European Community Council Directive (86-609/87-848 EEC) and recommendations of the French Ministère de l'Agriculture. Male wistar rats (260-280g) were purshased from Janvier (Le Genest Saint Isle, France). Cyclophilin D knockout (CypD KO) mice were a generous gift from the Laboratory of Michel Ovize (INSERM U1060, Lyon, France; Li et al., 2012).

\subsection{Isolation of rat and mouse ventricular myocytes}

Single ventricular cells were obtained from animals as described in the AfCS Procedure Protocols PP00000125. Animals (200 - $250 \mathrm{~g})$ were anesthetized with a solution of pentobarbital $(60 \mathrm{mg} / \mathrm{kg})$ and received heparin $(200 \mathrm{UI} / \mathrm{kg})$. The hearts were excised and retrograduatly perfused on a Langendorff apparatus with calcium-free oxygenated $\left(95 \% \mathrm{O}_{2}\right.$, $5 \% \mathrm{CO}_{2}$ ) perfusion buffer (in $\mathrm{mM}: \mathrm{NaCl} 113, \mathrm{KCl} 4.7, \mathrm{KH}_{2} \mathrm{PO}_{4} 0.6, \mathrm{Na}_{2} \mathrm{HPO}_{4} 0.6, \mathrm{MgSO}_{4}$ 1.2, $\mathrm{NaHCO}_{3} 12, \mathrm{KHCO}_{3}$ 10, HEPES 10, taurine 30, 2,3-butanedione monoxime 500, glucose 5.5, with $\mathrm{pH}$ adjusted to 7.4 with $\mathrm{NaOH} 1 \mathrm{~N}$ at $37^{\circ} \mathrm{C}$ ). Then, hearts were perfused for a few minutes with the same calcium-free perfusion buffer supplemented with $0.25 \mathrm{mg} / \mathrm{mL}$ of liberase blendzyme TM (Roche diagnostics, IN, USA), $0.14 \mathrm{mg} / \mathrm{mL}$ of trypsin (Invitrogen, Illkirch, France) and $12.5 \mu \mathrm{M}$ of calcium chloride. The left ventricle was removed and further dissected into small pieces, the cellular dissociation being achieved by gentle mechanical agitation in a stopping buffer (in mM: $\mathrm{NaCl} 113, \mathrm{KCl} 4.7, \mathrm{KH}_{2} \mathrm{PO}_{4} 0.6, \mathrm{Na}_{2} \mathrm{HPO}_{4} 0.6, \mathrm{MgSO}_{4}$ 1.2, $\mathrm{NaHCO}_{3} 12, \mathrm{KHCO}_{3}$ 10, HEPES 10, taurine 30, 2,3-butanedione monoxime 500, glucose 5.5, $\mathrm{CaCl}_{2} 12.5 \mu \mathrm{M}$ and bovine calf serum $10 \%$ with $\mathrm{pH}$ adjusted to 7.4 with $\mathrm{NaOH} 1 \mathrm{~N}$ at $37^{\circ} \mathrm{C}$ ). Extracellular calcium was added incrementally up to $1.0 \mathrm{mM}$. All cells studied were rod-shaped, had clear cross-striations and lacked any visible vesicles on their surfaces under observations with an optical microscope. 


\subsection{Measurement of myocyte contractility}

Myocytes were transferred to a warmed $\left(37^{\circ} \mathrm{C}\right)$ and continuously perfused cell chamber located on the stage of an inverted microscope (Nikon, Paris, France). The chamber was perfused with a physiological buffer containing (in $\mathrm{mM}$ ) $\mathrm{NaCl} 140, \mathrm{KCl} 5.4, \mathrm{CaCl}_{2} 1, \mathrm{MgCl}_{2}$ 0.8, HEPES 10 and glucose $5.6\left(\mathrm{pH}=7.4\right.$ at $\left.37^{\circ} \mathrm{C}\right)$.

Myocytes contraction was induced once per second $(1 \mathrm{~Hz})$ by platinum field electrodes that were placed in the cell chamber attached to a stimulator (Grass S88K, Grass Instruments, Trappes, France). Cell images were continuously acquired through a x 40 objective lens and transmitted to a 240 samples/s charge coupled device (CCD) video camera (Myocam, Ionoptix, Milton, MA, USA). The output from the CCD camera was displayed on a video monitor.

Myocytes were selected according to the following criteria (Kim et al., 1999): a rod shaped appearance with clear striations and no membrane blebs, no spontaneous contractions when stimulated in $1 \mathrm{mM}$ calcium buffer, steady diastolic length and contractile amplitude at basal stimulation rates. Sarcomere length was measured using a video motion edge detector (DSI 200, Ionoptix, Milton, MA, USA) and data were acquired at 240 samples/s. The camera images were converted to sarcomere length measurements by the video sarcomere detector and were analyzed by the data-acquisition system. Contractility was analyzed using an IonWizard data acquisition system (IonOptix). For sarcomere shortening, absolute twitch amplitude was measured as the difference between the systolic and the diastolic sarcomere length; sarcomere length shortening percentage was expressed as the ratio of absolute twitch amplitude to diastolic sarcomere length. Shortening velocity (-dl/dt) was used to measure the maximum velocity of sarcomere shortening during contraction and relengthening velocity 
$(+\mathrm{dl} / \mathrm{dt})$ was used to assess the maximum velocity of sarcomere relengthening during relaxation.

\subsection{Measurement of intracytosolic calcium concentration}

Intracytosolic calcium concentration was measured with a calcium ion-sensing system (Ionoptix, Milton, MA) by means of the fluorescent calcium indicator fura-2 (Invitrogen, Illkirch, France), using a dual-excitation fluorescence. The cells were loaded with $5 \mu \mathrm{M}$ of the membrane-permeant ester form of fura-2-AM, for $20 \mathrm{~min}$ at room temperature.

The fura-loaded myocytes were excited at $360 \mathrm{~nm}$ and $380 \mathrm{~nm}$, and the resulting fluorescence was measured at $510 \mathrm{~nm}$. The ratio of the fluorescence excited at $360 \mathrm{~nm}$ to that excited at $380 \mathrm{~nm}$ was independent of the intracellular fura-2 concentration, cell geometry, and excitation light intensity and reflected intracytosolic calcium concentration.

The fluorescence excited at $360 \mathrm{~nm}$ was independent of intracytosolic calcium concentration changes. During a typical data collection run, the $360 \mathrm{~nm}$ light was presented to the myocytes for $0.5 \mathrm{~s}$ at the beginning and at the end of the run, which lasted $250 \mathrm{~ms}$. Between these two points, only the $380 \mathrm{~nm}$ light was presented, and the fluorescence was acquired by the system. At each of these sampling points, a calculated $360 \mathrm{~nm}$ excited fluorescence was determined, using an interpolation of the $360 \mathrm{~nm}$ excited fluorescence collected at the beginning and at the end of the data collection run. The fluorescence ratio was formed by dividing the calculated $360 \mathrm{~nm}$ excited fluorescence by the measured $380 \mathrm{~nm}$ excited fluorescence. Changes in intracellular $\mathrm{Ca}^{2+}$ were analyzed using an IonWizard data acquisition system (IonOptix). For the ratio of fluorescence intensities of fura-2 AM $(360 \mathrm{~nm} / 380 \mathrm{~nm})$, the amplitude was measured as the difference between baseline and peak 
length; $\mathrm{Ca}^{2+}$ transient amplitude was expressed as the ratio of absolute amplitude to transient baseline.

\subsection{Measurement of mPTP opening in adult cardiomyocytes and cell viability}

Direct assessment of mPTP opening in cardiomyocytes was made by means of the established loading procedure of the cells with calcein acetoxymethyl ester (calcein-AM) and $\mathrm{CoCl}_{2}$ resulting in mitochondrial localization of calcein fluorescence (Katoh et al., 2002; Petronilli et al., 1999). Cells were loaded with $1 \mu \mathrm{M}$ calcein-AM for $30 \mathrm{~min}$ at $37^{\circ} \mathrm{C}$ in $2 \mathrm{ml}$ of M199 medium, pH 7.4, supplemented with $1 \mathrm{mM} \mathrm{CoCl}_{2}$. To determine cell death, cells were co-loaded with propidium iodide $(5 \mu \mathrm{M})$, which permeates only the damaged cells. For detection of calcein fluorescence, a 460 to $490 \mathrm{~nm}$ excitation and a $510 \mathrm{~nm}$ emission filters were used. Propidium iodide fluorescence was excited at 520 to $550 \mathrm{~nm}$ and recorded at $580 \mathrm{~nm}$. Photographs were taken using an inverted fluorescence microscope (Olympus IX-81, Rungis, France). Measurements of calcein and propidium iodide fluorescence intensities were performed for each image using a digital epifluorescence imaging software (Cell P; Olympus, Rungis, France). Fluorescence was integrated over a region of interest $\left(\approx 80 \mu \mathrm{m}^{2}\right)$ for each cardiomyocyte, and a fluorescence background corresponding to an area without cells was removed. For comparative purposes, the fluorescence intensity minus background was normalized according to the initial fluorescence value.

Results are expressed as means \pm s.e.m of seven experiments. For each experiment, we calculated the response observed by averaging the fluorescence changes obtained from all of the cardiomyocytes contained in three fields (at least 50-75 cells).

\subsection{Detection of reactive oxygen species in cardiomyocytes}


To evaluate ROS formation, cardiomyocytes were loaded either with $5 \mu \mathrm{M}$ of the nonfluorescent probe 2,7-dichlorodihydrofluorescein-diacetate (DCFH-DA; Invitrogen, Illkirch, France) for $30 \mathrm{~min}$ in the dark or with $1 \mu \mathrm{M}$ of the fluorogenic dye MitoSOX. DCFH-DA is cleaved by cellular esterases and is oxidized by ROS (mainly $\mathrm{H}_{2} \mathrm{O}_{2}$ and ${ }^{\circ} \mathrm{OH}$ ) and yields the fluorescent product DCF. MitoSOX is selectively targeted to the mitochondria where it is oxidized by superoxide and exhibits red fluorescence. After incubation, DCF fluorescence was measured using 460 to $490 \mathrm{~nm}$ excitation and $510 \mathrm{~nm}$ emission filters. MitoSOX fluorescence was excited at 520 to $550 \mathrm{~nm}$ and recorded at $580 \mathrm{~nm}$. Photographs were taken using an inverted fluorescence microscope (Olympus IX-81, Rungis, France). Measurement of DCF or MitoSOX fluorescence intensity was performed for each image using a digital epifluorescence imaging software (Cell P; Olympus, Rungis, France). Fluorescence was integrated over a region of interest $\left(\approx 80 \mu \mathrm{m}^{2}\right)$ for each cardiomyocyte, and a fluorescence background corresponding to an area without cells was removed.

The results are expressed as means \pm s.e.m of 5-7 experiments. For each experiment, we calculated the response observed by averaging the fluorescence changes obtained from all of the cardiomyocytes contained in three fields (at least 50-75 cells).

\subsection{Experimental protocol}

To determine the optimal toxic concentration of doxorubicin in cells, isolated cardiomyocytes were continuously exposed to increasing concentrations of doxorubicin i.e., from 0.25 to $20 \mu \mathrm{M}$ for 18 hours and the results were compared to control cells (non exposed to doxorubicin). 
In order to analyse the effect of doxorubicin on mPTP opening, ROS production and consequent impact on contractile dysfunction and cell viability, cardiomyocytes were pretreated with pharmacological agents targeting these processes: $1 \mu \mathrm{M}$ cyclosporin $\mathrm{A}(\mathrm{CsA})$ (Assaly et al., 2012) or an antioxidant mixture containing $5 \mu \mathrm{M}$ resveratrol and $5 \mathrm{mM} \mathrm{N}$ acetylcystein (Sigma, Saint Quentin Fallavier, France) (Andersson et al., 2011; Horstkotte et al., 2011) before addition of $20 \mu \mathrm{M}$ doxorubicin. The protective effect of TSPO ligands on the deleterious effects of doxorubicin was determined by pretreating cardiomyocytes with either increasing concentrations of 4'-chlorodiazepam (Sigma, Saint Quentin Fallavier, France) or TRO40303 (synthesized by Synchem, Dijon, France) or fixed concentrations of the drugs (1 $\mu \mathrm{M}$ for 4'-chlorodiazepam and $3 \mu \mathrm{M}$ for TRO40303) before exposure to $20 \mu \mathrm{M}$ doxorubicin. These last concentrations were chosen because they were the lowest efficient concentrations in the concentration-dependent experiments and also because they showed cardioprotective effects in previous studies (Obame et al., 2007; Schaller et al., 2010).

\subsection{Data analysis}

All data were expressed as means \pm s.e.m. Comparisons of the data between different groups were performed by one way ANOVA followed by Sheffe with significant differences taken at $\mathrm{p}<0.05$. 


\section{Results}

\subsection{Doxorubicin induces contractile dysfunction and cell death in isolated adult rat}

cardiomyocytes

To determine the concentration-dependent effects of doxorubicin on contractile dysfunction and cardiomyocyte death, cells were first exposed to increasing concentrations of doxorubicin (from 0.25 to $20 \mu \mathrm{M}$ ) for 18 hours.

As shown in Table 1, the average sarcomere length of cells used in this study was not significantly different among groups. In this model, treatments with 1 and $5 \mu \mathrm{M}$ doxorubicin caused a paradoxical increase in cardiomyocyte contraction (Fig 1A). At concentrations higher than $5 \mu \mathrm{M}$, contractility as well as velocities of contraction and relaxation (Fig 1A, B and C) were significantly decreased. This was associated with a decrease in cytosolic calcium concentration (Fig 1D). This deleterious effect was confirmed by the study of the cellular contraction/relaxation cycle. Doxorubicin $(20 \mu \mathrm{M})$ prolonged the cellular contraction/relaxation cycle duration by $36.5 \%(0.20 \pm 0.01$ vs. $0.30 \pm 0.03 \mathrm{~ms}$ for control and doxorubicin, respectively; $\mathrm{p}<0.05$; Fig $1 \mathrm{C}$ ) as shown by the time necessary to return to the basal value. As shown in figure $1 \mathrm{E}$, doxorubicin reduced cell viability in a concentrationdependent manner $(\mathrm{p}<0.05$ from 5 to $20 \mu \mathrm{M})$.

In order to work with an optimal window of improvement, the concentration of $20 \mu \mathrm{M}$ was used in the next experiments to study the effect of TSPO ligands and control compounds, as it induced the most significant deleterious effect.

\subsection{Doxorubicin-induced contractile dysfunction and cell death are closely associated with} ROS production and mPTP opening. 
As ROS generation was suggested to be a major cause of doxorubicin-induced cell death (Davies et al., 1986; Mimnaugh et al., 1985; Simunek et al., 2009; Wallace, 2003), we monitored the production of ROS in cardiomyocytes exposed to increasing concentrations of doxorubicin for 18 hours. The study confirms that doxorubicin enhances ROS production in a concentration-dependent manner (Fig 2A) as observed with the fluorescent probe DCF that is commonly utilized to detect generalized ROS production. The increase in ROS production was also found with MitoSOX that specifically revealed the production of superoxide in mitochondria (Fig 2B). Preincubation of cardiomyocytes with a mixture of antioxidant agents (resveratrol $(5 \mu \mathrm{M})$ and $\mathrm{N}$-acetylcysteine $(5 \mathrm{mM}))$ prevented the increase in ROS production induced by $20 \mu \mathrm{M}$ doxorubicin (Fig 2B). Antioxidant treatment also prevented the doxorubicin-induced decrease in intracellular $\mathrm{Ca}^{2+}$ as measured by the fura-2 ratio (Fig $2 \mathrm{C}$ ), mPTP opening (Fig 2D) and preserved contractile function. Indeed, antioxidants restored cell shortening (Fig 2E and 2G) and improved velocities of contraction and relaxation (Fig 2F) but had no significant effect on the duration of the cellular contraction/relaxation cycle $(0.30 \pm 0.03$ vs. $0.25 \pm 0.02 \mathrm{~ms}$ for doxorubicin and doxorubicin + antioxidants, respectively, Fig 2G). Antioxidant treatment also improved cardiomyocyte viability as it counteracted the increase in propidium iodide fluorescence intensity induced by doxorubicin (Fig $2 \mathrm{H}$ ). Antioxidant pretreatment alone had no significant effect on any of these parameters.

In parallel to ROS generation, doxorubicin treatment dose-dependently induced mPTP opening monitored by a loss of mitochondrial calcein fluorescence (Fig 3A). This was confirmed in the presence of the specific mPTP inhibitor, cyclosporin A, which was able to blunt this effect induced by $20 \mu \mathrm{M}$ doxorubicin (Fig 3B), although cyclosporin A had no effect on ROS production (Fig 3C) or decreases in intracellular calcium levels (Fig 3D) induced by doxorubicin. Cyclosporin A treatment maintained cell shortening to its control level (Fig 3E and 3G) and prevented the doxorubicin-induced prolongation of the time 
necessary for the sarcomere length to return to the basal value $(0.30 \pm 0.03$ vs. $0.21 \pm 0.02 \mathrm{~ms}$ for doxorubicin and doxorubicin + cyclosporin A, respectively; p<0.05; Fig 3G) but had no effect on contraction and relaxation velocities (Fig 3F). Cyclosporin A also improved survival as it counteracted the increase in propidium iodide fluorescence intensity induced by doxorubicin (Fig 3H). Moreover, it should be noted that pretreatment with cyclosporin A had no proper effect on any of these parameters.

\subsection{4'-Chlorodiazepam and TRO40303 prevention of doxorubicin-induced contractile} dysfunction and cell death involves inhibition of ROS production and mPTP opening.

In order to see whether TSPO ligands might prevent doxorubicin-induced contractile dysfunction and cell death, cardiomyocytes were pre-incubated for $30 \mathrm{~min}$ with increasing concentrations of 4'-chlorodiazepam or TRO40303 (Schaller et al., 2010) before doxorubicin treatment (20 $\mu \mathrm{M}$ for 18 hours). Both 4'-chlorodiazepam and TRO40303 prevented doxorubicin-induced alterations in cell contraction (Fig 4A, 4B, 4C, 4D), mPTP opening (Fig. 5A) and cell death (5B) in a concentration-dependent manner.

It should be noted that these drugs did not show any proper effect on cell contraction, as, they had no significant effect on cardiomyocyte contractile performance compared to controls (Fig 4A) and did not modify the mean cell sarcomere length (Table 1). At the same concentrations, 4'-chlorodiazepam and TRO40303 had no significant effect on the duration of the cellular contraction/relaxation cycle altered by doxorubicin $(0.30 \pm 0.03$ vs. $0.24 \pm 0.01 \mathrm{~ms}$ for doxorubicin and doxorubicin +4 '-chlorodiazepam, respectively and $0.30 \pm 0.03$ vs. $0.25 \pm 0.02 \mathrm{~ms}$ for doxorubicin and doxorubicin + TRO40303, respectively; Fig 4C and 4D) but prevented the decrease in fura- 2 ratio induced by doxorubicin, maintaining calcium levels similar to those observed in control cells (Fig 5C). In the same way, 4'-chlorodiazepam and TRO40303 attenuated ROS production (Fig. 5D). 
In order to further investigate the action mechanism of TSPO ligands and more particularly to see whether the protection from TSPO ligands overlaps with cyclosporin A, additional experiments were performed with cardiomyocytes isolated from CypD $\mathrm{KO}$ mice. As well as observed with cardiomyocytes issued from rat hearts, doxorubicin induced mPTP opening in a concentration-dependent manner in cardiomyocytes isolated from wild type and $\mathrm{KO}$ mice but the effect was more pronounced in WT mice (Fig. 6A). This was associated with an enhanced production of ROS at the mitochondrial level as demonstrated by the increase in MitoSOX fluorescence (Fig. 6B) and a decrease in myocytes contractility (Fig. 6 C). TRO40303 inhibited mPTP opening in KO mice, reduced ROS production and improved the contractile performance of the myocytes whereas cyclosporin A did not (Fig. 6A, B and C).

\section{Discussion}

The major findings of the present study are as follows: 1) TSPO ligands prevent doxorubicin-induced contractile dysfunction and inhibit cell death, 2) these effects are associated with a decrease in ROS and MPTP opening and 3) both were coupled with normalization of cytosolic calcium dysfunction induced by doxorubicin.

In the present study we used an acute model of doxorubicin-induced cardiotoxicity. Clinically, doxorubicin-induced cardiotoxicity can be characterized by acute myocardial injury occurring immediately after an initial treatment. Alternatively, chronic cardiotoxicity is characterized by congestive heart failure, ventricular dysfunction and arrhythmia and may occur years to decades after anthracyline treatment (Lipshultz et al., 1991; Schwartz et al., 1987; Steinherz et al., 1991). It should be reminded that the long term effects of the drug are the consequence of its acute toxicity that further progresses with repeated exposure. Thus preventing the acute cardiotoxicity of the drug is an important approach to develop 
cardioprotective therapies against doxorubicin toxicity. The paradoxical positive inotropic effect that we observed in freshly isolated cardiomyocytes cultured with low concentrations of doxorubicin $(1$ and $5 \mu \mathrm{M})$ might reflect the increases in both systolic and diastolic functions and electrocardiographic changes, observed in patients 1 to 4 hours after doxorubicin treatment (Brown et al., 1989). Timolati et al. (Timolati et al., 2006) have shown that treatment with $1 \mu \mathrm{M}$ doxorubicin for 18 hours caused partial degradation of sarcoplasmic reticulum $\mathrm{Ca}^{2+}$-ATPase (SERCA) without modification of the sarcolemnal reticulum calcium content. It has been suggested that such a positive inotropic effect of doxorubicin is linked to an acute ROS production leading to opening of L-type calcium channels and subsequent increased in cardiac contractility (Campbell et al., 1996; Thollon et al., 1995; Wang \& Korth, 1995). In contrast, at concentrations higher than $5 \mu \mathrm{M}$, doxorubicin exhibits a well described negative inotropic effect associated with a decrease in calcium amplitude. This is in line with the present results and the data of Timolati et al. (Timolati et al., 2006) who showed that the anthracycline-induced negative inotropy mainly depends on the down-regulation of the SERCA pump associated with a decrease in $90 \%$ time of relaxation and a decrease in sarcolemnal reticulum calcium loading.

One of the proposed mechanisms for doxorubicin-induced cardiac dysfunction is oxidation of cellular components via ROS formation ( Minotti et al., 2004). Indeed, the quinone moiety of doxorubicin is prone to the generation of oxygen radicals through enzymatic mechanism involving mitochondrial respiratory chain (Gutierrez PL, 2000). A number of studies has also suggested that doxorubicin mediated alteration in calcium homeostasis may be one of the possible mechanisms of its cardiotoxicity (Shadle et al. 2000). The present study confirms that ROS production is a crucial event occurring during doxorubicin treatment and is associated with induction of mPTP opening which plays a key role in the life and death of cells (Javadov et al., 2009; Leung \& Halestrap, 2008; Zorov et al., 2009). The mPTP opens 
under conditions of elevated mitochondrial calcium, especially when associated with oxidative stress, i.e., exactly the conditions occurring during chronic doxorubicin cardiotoxicity (Cardoso et al., 2008; Tokarska-Schlattner et al., 2006; Wallace, 2007). Pharmacological strategies developed to inhibit mPTP opening have demonstrated their protective efficacy (Morin et al., 2009; Ovize et al., 2010) more particularly during ischemia/reperfusion. Using 4'-chlorodiazepam and TRO40303 as TSPO ligands it has been recently reported that TSPO is an interesting target to reduce myocardial infarct size in animal models of ischemia/reperfusion (Obame et al., 2007; Schaller et al., 2010). In the present work, we report for the first time to our knowledge that TSPO is also a relevant target to prevent doxorubicin toxicity and that the mechanism of cardioprotection from this drug afforded by TSPO ligands is linked to limitation of mitochondrial membrane permeabilization and ROS production. TSPO modulation could counteract the effects of $\mathrm{H}_{2} \mathrm{O}_{2^{-}}$or ischemia/reperfusion-induced impairment of cardiac mitochondrial oxidative phosphorylation as well as apoptosis (Obame et al., 2007; Schaller et al., 2010; Leducq et al., 2003), indicating that TSPO modulation prevents ROS generation. Here, we demonstrate that 4'chlorodiazepam and TRO40303 decrease the production of ROS during doxorubicin treatment, which may be one of the mechanisms by which these ligands decrease mPTP opening since similar protection was provided by antioxidant agents.

In addition, the data obtained with cardiomyocytes from CypD KO mice show that the protection of TSPO ligands does not overlap with cyclosporin A as these ligands inhibit ROS production and mPTP opening whereas cyclosporin A does not. This demonstrates that these ligands do not interact with CypD and reinforces the hypothesis of an inhibition of ROS production.

Interestingly, these effects were concomitant of a mechanical improvement in adult cardiomyocytes as pretreatment with TSPO ligands blunted the contractile dysfunction 
induced by doxorubicin. The pattern of cardioprotection induced by these ligands was similar although their binding domains on TSPO are different. TRO40303 interacts specifically at the cholesterol binding site of the protein, while the TSPO benzodiazepine binding site is targeted by 4'-chlorodiazepam (Lacapere et al., 2001; Kalivendi et al., 2001). The fact that the decrease in calcium amplitude induced by doxorubicin was counteracted by TSPO ligands suggests that these agents could prevent perturbations in calcium homeostasis, which are known to interfere with muscle contraction and relaxation. This effect of TSPO ligands is most likely due to a decrease in ROS production rather than a direct inhibition of mPTP opening as antioxidant agents exhibit a similar effect whereas it was not obtained in the presence of cyclosporin A, as observed here with CypD KO mice. These findings are also corroborated by several studies demonstrating a close relationship between calcium homeostasis and ROS production since doxorubicin-induced ROS production is reduced by the calcium chelator BAPTA (Kalivendi et al., 2001; Kalivendi et al., 2005). In addition, antioxidant properties of calcium channel blockers have been observed in in vitro and in vivo studies (Umemoto et al., 2004). Recent data also suggested that 4'-chlorodiazepam is able to blunt the decrease in cell contractility and to prevent reperfusion arrhythmias in a model of ischemia-reperfusion through a mechanism involving inhibition of the mitochondrial inner membrane anion channel (IMAC) and recovery of the mitochondrial inner membrane potential (Akar et al., 2005). However, high concentrations of 4'-chlorodiazepam were required to observe this effect $(32-100 \mu \mathrm{M})$.

In conclusion, this study provides novel evidence that two TSPO ligands, 4'chlorodiazepam and TRO40303, can significantly reduce the incidence of contractile dysfunction and cell death during doxorubicin treatment by inhibiting ROS production and mPTP opening. Modulation of TSPO may represent a new pharmacological strategy for 
developing cytoprotective agents against cell death and contractile dysfunction induced by doxorubicin.

\section{Acknowledgments}

The authors are greatly indebted to Pr Michel Ovize (Inserm U 1060) from Lyon University for the generous supply of CypD KO mice and their respective WT. They are also indebted to Sophie Nunes and Clément Montpied for their excellent technical assistance.

Conflicts of interest: Alain Berdeaux has served as consultant and received honorarium from TROPHOS. Rebecca M. Pruss holds shares in TROPHOS. 


\section{References}

Akar, F.G., Aon, M.A., Tomaselli, G.F., O'Rourke., B. 2005. The mitochondrial origin of postischemic arrhythmias. J. Clin. Invest. 115, 3527-35.

Andersson, D.C., Fauconnier, J., Yamada, T., Lacampagne, A., Zhang, S.J., Katz, A. et al. 2011. Mitochondrial production of reactive oxygen species contributes to the beta-adrenergic stimulation of mouse cardiomyocytes. J. Physiol. 589, 1791-801.

Arola, O.J., Saraste, A., Pulkki, K., Kallajoki, M., Parvinen, M., Voipio-Pulkki, L.M. 2000. Acute doxorubicin cardiotoxicity involves cardiomyocyte apoptosis. Cancer Res. 60, 178992.

Assaly, R., de Tassigny, A., Paradis, S., Jacquin, S., Berdeaux, A., Morin, D. 2012. Oxidative stress, mitochondrial permeability transition pore opening and cell death during hypoxiareoxygenation in adult cardiomyocytes. Eur. J. Pharmacol. 675, 6-14.

Berthiaume, J.M., Wallace, K.B. 2007. Adriamycin-induced oxidative mitochondrial cardiotoxicity. Cell Biol. Toxicol. 23, 15-25.

Brown, K.A., Blow, A.J., Weiss, R.M., Stewart, J.A. 1989. Acute effects of doxorubicin on human left ventricular systolic and diastolic function. Am. Heart J. 118, 979-82.

Campbell, D.L., Stamler, J.S., Strauss, H.C. 1996. Redox modulation of L-type calcium channels in ferret ventricular myocytes. Dual mechanism regulation by nitric oxide and Snitrosothiols. J. Gen. Physiol. 108, 277-93.

Cardoso, S., Santos, R.X., Carvalho, C., Correia, S., Pereira, G.C., Pereira, S.S. et al. 2008. Doxorubicin increases the susceptibility of brain mitochondria to $\mathrm{Ca}(2+)$-induced permeability transition and oxidative damage. Free Radic. Biol. Med. 45, 1395-402.

Childs, A.C., Phaneuf, S.L., Dirks, A.J., Phillips, T., Leeuwenburgh, C. 2002. Doxorubicin treatment in vivo causes cytochrome $\mathrm{C}$ release and cardiomyocyte apoptosis, as well as increased mitochondrial efficiency, superoxide dismutase activity, and Bcl-2:Bax ratio. Cancer Res. 62, 4592-8.

Davies, K.J., Doroshow, J.H. 1986. Redox cycling of anthracyclines by cardiac mitochondria. I. Anthracycline radical formation by NADH dehydrogenase. J. Biol. Chem. 261, 3060-3067. 
Delpy, E., Hatem, S.N., Andrieu, N., de Vaumas, C., Henaff, M., Rucker-Martin, C. et al. . 1999. Doxorubicin induces slow ceramide accumulation and late apoptosis in cultured adult rat ventricular myocytes. Cardiovasc. Res. 43, 398-407.

Doroshow, J.H., Davies, K.J. 1986. Redox cycling of anthracyclines by cardiac mitochondria. II. Formation of superoxide anion, hydrogen peroxide, and hydroxyl radical. J. Biol. Chem. 261, 3068-74.

Ferreira, A.L., Matsubara, L.S., Matsubara, B.B. 2008. Anthracycline-induced cardiotoxicity. Cardiovasc Hematol Agents Med. Chem. 6, 278-281.

Gavish, M., Bachman, I., Shoukrun, R., Katz, Y., Veenman, L., Weisinger, G. et al. 1999. Enigma of the peripheral benzodiazepine receptor. Pharmacol. Rev. 51, 629-650.

Gutierrez, P.L. 2000. The role of NAD(P)H oxidoreductase (DT-Diaphorase) in the bioactivation of quinone-containing antitumor agents: a review. Free Radic. Biol. Med. 29, 263-275.

Halestrap, A.P. 2009. What is the mitochondrial permeability transition pore? J. Mol. Cell. Cardiol. 46, 821-831.

Horstkotte, J., Perisic, T., Schneider, M., Lange, P., Schroeder, M., Kiermayer, C. et al. 2011. Mitochondrial thioredoxin reductase is essential for early postischemic myocardial protection. Circulation. 124, 2892-2902.

Javadov, S., Karmazyn, M., Escobales, N. 2009. Mitochondrial permeability transition pore opening as a promising therapeutic target in cardiac diseases. J. Pharmacol. Exp. Ther. 330, 670-678.

Johnson, M.D., Wang, J.K., Morgan, J.I., Spector, S. 1986. Downregulation of [3H]Ro5-4864 binding sites after exposure to peripheral-type benzodiazepines in vitro. J. Pharmacol. Exp. Ther. 238,855-859.

Kalivendi, S.V., Kotamraju, S., Zhao, H., Joseph, J., Kalyanaraman, B. 2001. Doxorubicininduced apoptosis is associated with increased transcription of endothelial nitric-oxide synthase. Effect of antiapoptotic antioxidants and calcium. J. Biol. Chem. 276, 47266-47276. 
Kalivendi, S.V., Konorev, E.A., Cunningham, S., Vanamala, S.K., Kaji, E.H., Joseph, J. et al. 2005. Doxorubicin activates nuclear factor of activated T-lymphocytes and Fas ligand transcription: role of mitochondrial reactive oxygen species and calcium. Biochem. J. 389, 527-539.

Kalyanaraman, B., Joseph, J., Kalivendi, S., Wang, S., Konorev, E., Kotamraju, S. 2002. Doxorubicin-induced apoptosis: implications in cardiotoxicity. Mol. Cell. Biochem. 234-235, $119-124$.

Katoh, H., Nishigaki, N., Hayashi, H. 2002. Diazoxide opens the mitochondrial permeability transition pore and alters $\mathrm{Ca} 2+$ transients in rat ventricular myocytes. Circulation. 105, 26662671.

Keefe, D.L. 2001. Anthracycline-induced cardiomyopathy. Semin. Oncol. 28, 2-7.

Kim, S.J., Iizuka, K., Kelly, R.A., Geng, Y.J., Bishop, S.P., Yang, G. et al. 1999. An alphacardiac myosin heavy chain gene mutation impairs contraction and relaxation function of cardiac myocytes. Am. J. Physiol. 276, H1780-1787.

Lacapere, J.J., Delavoie, F., Li, H., Peranzi, G., Maccario, J., Papadopoulos, V. et al. 2001. Structural and functional study of reconstituted peripheral benzodiazepine receptor. Biochem. Biophys. Res. Commun. 284, 536-541.

Lebrecht, D., Geist, A., Ketelsen, U.P., Haberstroh, J., Setzer, B., Walker, U.A. 2007. Dexrazoxane prevents doxorubicin-induced long-term cardiotoxicity and protects myocardial mitochondria from genetic and functional lesions in rats. Br. J. Pharmacol. 151, 771-778.

Leducq, N., Bono, F., Sulpice, T., Vin, V., Janiak, P., Fur, G.L. et al. 2003. Role of peripheral benzodiazepine receptors in mitochondrial, cellular, and cardiac damage induced by oxidative stress and ischemia-reperfusion. J. Pharmacol. Exp. Ther. 306, 828-837.

Leung, A.W., Halestrap, A.P. 2008. Recent progress in elucidating the molecular mechanism of the mitochondrial permeability transition pore. Biochim. Biophys. Acta. 1777, 946-952.

Li, B., Chauvin, C., De Paulis, D., De Oliveira, F., Gharib, A., Vial, G. et al. 2012. Inhibition of complex I regulates the mitochondrial permeability transition through a phosphatesensitive inhibitory site masked by cyclophilin D.Biochim. Biophys. Acta. 1817:1628-1634. 
Lim, C.C., Zuppinger, C., Guo, X., Kuster, G.M., Helmes, M., Eppenberger, H.M. et al. 2004. Anthracyclines induce calpain-dependent titin proteolysis and necrosis in cardiomyocytes. $\mathrm{J}$. Biol. Chem. 279, 8290-8299.

Lipshultz, S.E., Colan, S.D., Gelber, R.D., Perez-Atayde, A.R., Sallan, S.E., Sanders, S.P. 1991. Late cardiac effects of doxorubicin therapy for acute lymphoblastic leukemia in childhood. N. Engl. J. Med. 324, 808-815.

Mimnaugh, E.G., Trush, M.A., Bhatnagar, M., Gram, T.E. 1985. Enhancement of reactive oxygen-dependent mitochondrial membrane lipid peroxidation by the anticancer drug adriamycin. Biochem. Pharmacol. 34, 847-856.

Minotti, G., Menna, P., Salvatorelli, E., Cairo, G., Gianni, L. 2004. Anthracyclines: molecular advances and pharmacologic developments in antitumor activity and cardiotoxicity. Pharmacol. Rev. 56, 185-229.

Montaigne, D., Marechal, X., Baccouch, R., Modine, T., Preau, S., Zannis, K. et al. 2010. Stabilization of mitochondrial membrane potential prevents doxorubicin-induced cardiotoxicity in isolated rat heart. Toxicol. Appl. Pharmacol. 244, 300-307.

Morin, D., Assaly, R., Paradis, S., Berdeaux, A. 2009. Inhibition of mitochondrial membrane permeability as a putative pharmacological target for cardioprotection. Curr. Med. Chem. 16, 4382-4398.

Obame, F.N., Zini, R., Souktani, R., Berdeaux, A., Morin, D. 2007. Peripheral benzodiazepine receptor-induced myocardial protection is mediated by inhibition of mitochondrial membrane permeabilization. J. Pharmacol. Exp. Ther. 323, 336-345

Olson, R.D., Mushlin, P.S. 1990. Doxorubicin cardiotoxicity: analysis of prevailing hypotheses. Faseb J. 4, 3076-3086.

Ovize, M., Baxter, G.F., Di Lisa, F., Ferdinandy, P., Garcia-Dorado, D., Hausenloy, D.J. et al. 2010. Postconditioning and protection from reperfusion injury: where do we stand? Position paper from the Working Group of Cellular Biology of the Heart of the European Society of Cardiology. Cardiovasc. Res. 87, 406-423. 
Papadopoulos, V., Mukhin, A.G., Costa, E., Krueger, K.E. 1990. The peripheral-type benzodiazepine receptor is functionally linked to Leydig cell steroidogenesis. J. Biol. Chem. $265,3772-3779$.

Papadopoulos, V., Baraldi, M., Guilarte, T.R., Knudsen, T.B., Lacapere, J.J., Lindemann, P. et al. 2006. Translocator protein $(18 \mathrm{kDa})$ : new nomenclature for the peripheral-type benzodiazepine receptor based on its structure and molecular function. Trends Pharmacol. Sci. 27, 402-409.

Petronilli, V., Miotto, G., Canton, M., Brini, M., Colonna, R., Bernardi, P. et al. 1999. Transient and long-lasting openings of the mitochondrial permeability transition pore can be monitored directly in intact cells by changes in mitochondrial calcein fluorescence. Biophys. J. 76, 725-734.

Sawyer, D.B., Fukazawa, R., Arstall, M.A., Kelly, R.A. 1999. Daunorubicin-induced apoptosis in rat cardiac myocytes is inhibited by dexrazoxane. Circ. Res. 84, 257-265.

Schaller, S., Paradis, S., Ngoh, G.A., Assaly, R., Buisson, B., Drouot, C. et al. 2010. TRO40303, a new cardioprotective compound, inhibits mitochondrial permeability transition. J. Pharmacol. Exp. Ther. 333, 696-706.

Schwartz, R.G., McKenzie, W.B., Alexander, J., Sager, P., D'Souza, A., Manatunga, A. et al. 1987. Congestive heart failure and left ventricular dysfunction complicating doxorubicin therapy. Seven-year experience using serial radionuclide angiocardiography. Am. J. Med. 82, 1109-1118.

Shadle, S.E., Bammel, B.P., Cusack, B.J., Knighton, R.A., Olson, S.J., Mushlin, P.S. et al. 2000. Daunorubicin cardiotoxicity: evidence for the importance of the quinone moiety in a free-radical-independent mechanism. Biochem. Pharmacol. 60, 1435-1444.

Simunek, T., Sterba, M., Popelova, O., Adamcova, M., Hrdina, R., Gersl, V. 2009. Anthracycline-induced cardiotoxicity: overview of studies examining the roles of oxidative stress and free cellular iron. Pharmacol. Rep. 61, 154-171.

Singal, P.K., Iliskovic, N. 1998. Doxorubicin-induced cardiomyopathy. N. Engl. J. Med. 339, 900-905. 
Thollon, C., Iliou, J.P., Cambarrat, C., Robin, F., Vilaine, J.P. 1995. Nature of the cardiomyocyte injury induced by lipid hydroperoxides. Cardiovasc. Res. 30, 648-655.

Timolati, F., Ott, D., Pentassuglia, L., Giraud, M.N., Perriard, J.C., Suter, T.M. et al. 2006. Neuregulin-1 beta attenuates doxorubicin-induced alterations of excitation-contraction coupling and reduces oxidative stress in adult rat cardiomyocytes. J. Mol. Cell. Cardiol. 41, 845-854.

Tokarska-Schlattner, M., Zaugg, M., da Silva, R., Lucchinetti, E., Schaub, M.C., Wallimann, T. et al. 2005. Acute toxicity of doxorubicin on isolated perfused heart: response of kinases regulating energy supply. Am. J. Physiol. Heart Circ. Physiol. 289, H37-H47.

Tokarska-Schlattner, M., Zaugg, M., Zuppinger, C., Wallimann, T., Schlattner, U. 2006. New insights into doxorubicin-induced cardiotoxicity: the critical role of cellular energetics. J. Mol. Cell. Cardiol. 41, 389-405.

Tsang, W.P., Chau, S.P., Kong, S.K., Fung, K.P., Kwok, T.T. 2003. Reactive oxygen species mediate doxorubicin induced p53-independent apoptosis. Life Sci. 73, 2047-2058.

Steinherz, L.J., Steinherz, P.G., Tan, C.T., Heller, G., Murphy, M.L. 1991. Cardiac toxicity 4 to 20 years after completing anthracycline therapy. Jama. 266, 1672-1677.

Umemoto, S., Tanaka, M., Kawahara, S., Kubo, M., Umeji, K., Hashimoto, R. et al. 2004. Calcium antagonist reduces oxidative stress by upregulating $\mathrm{Cu} / \mathrm{Zn}$ superoxide dismutase in stroke-prone spontaneously hypertensive rats. Hypertens. Res. 27, 877-885.

Wallace, K.B. 2003. Doxorubicin-induced cardiac mitochondrionopathy. Pharmacol. Toxicol. 93, 105-115.

Wallace, K.B. 2007. Adriamycin-induced interference with cardiac mitochondrial calcium homeostasis. Cardiovasc. Toxicol. 7, 101-107.

Wang, Y.X., Korth, M. 1995. Effects of doxorubicin on excitation-contraction coupling in guinea pig ventricular myocardium. Circ. Res. 76, 645-653.

Xiao, J., Liang, D., Zhang, H., Liu, Y., Li, F., Chen, Y.H. 2010. 4'-Chlorodiazepam, a translocator protein $(18 \mathrm{kDa})$ antagonist, improves cardiac functional recovery during postischemia reperfusion in rats. Exp. Biol. Med. 235, 478-486. 
Zoratti, M., Szabo, I. 1995. The mitochondrial permeability transition. Biochim. Biophys. Acta. 1241, 139-176.

Zorov, D.B., Juhaszova, M., Yaniv, Y., Nuss, H.B., Wang, S., Sollott, S.J. 2009. Regulation and pharmacology of the mitochondrial permeability transition pore. Cardiovasc. Res. 83, 213-225. 


\section{Legends for Figures}

Fig. 1: Effect of doxorubicin on contractile function and cell death.

A and B: cardiomyocytes were cultured for 18 hours in the presence of increasing concentrations of doxorubicin (Dox), and then cell shortening (A) and maximal velocities of contraction and relaxation (B) were measured in $1 \mathrm{~Hz}$ paced cells.

C: typical examples of cardiomyocyte contractions without or with $20 \mu \mathrm{M}$ Dox treatment.

D: cardiomyocytes were loaded with $5 \mu \mathrm{M}$ fura-2-AM, were excited at $360 \mathrm{~nm}$ and $380 \mathrm{~nm}$, and the resulting fluorescence was measured at $510 \mathrm{~nm}$.

E: cells were loaded with propidium iodide and cultured for 18 hours in the presence of increasing concentrations of Dox. Cell death was determined by evaluating propidium iodide fluorescence.

Each value is the mean \pm SEM of five independent experiments including 30-45 cells. *: $\mathrm{p}<0.05$ versus control $(\mathrm{Ctl})$ cells.

Fig. 2: Doxorubicin-induced ROS production, mPTP opening, contractile dysfunction and cell death were prevented by antioxidant agents.

A: cardiomyocytes were cultured for 18 hours in the presence of doxorubicin (Dox), and then loaded with $5 \mu \mathrm{M}$ DCF-DA or $1 \mu \mathrm{M}$ MitoSOX. At the end of the incubation period, ROS production was evaluated by measuring DCF or MitoSOX fluorescence.

B-H: cardiomyocytes were pretreated with an antioxidant cocktail (resveratrol, $5 \mu \mathrm{M}+\mathrm{N}-$ acetylcystein, $5 \mathrm{mM}, \mathrm{AO}$ ) and then cultured for 18 hours in the presence of $20 \mu \mathrm{M}$ Dox.

B: cardiomyocytes were loaded with $5 \mu \mathrm{M}$ DCF-DA or $1 \mu \mathrm{M}$ MitoSOX and ROS production was evaluated by measuring DCF or MitoSOX fluorescence. C: cardiomyocytes were loaded with $5 \mu \mathrm{M}$ fura-2-AM, were excited at $360 \mathrm{~nm}$ and $380 \mathrm{~nm}$, and the resulting fluorescence was measured at $510 \mathrm{~nm}$. D: cardiomyocytes were loaded with $1 \mu \mathrm{M}$ calcein-AM 
supplemented with $1 \mathrm{mM} \mathrm{CoCl} 2$ and $\mathrm{mPTP}$ opening was evaluated by measuring calcein fluorescence. E and F: cell shortening (E) and maximal velocities of contraction and relaxation (F) were measured in $1 \mathrm{~Hz}$ paced cells. G: Typical examples of cardiomyocyte contractions without or with $20 \mu \mathrm{M}$ Dox or Dox + AO treatment. H: Cells were loaded with propidium iodide and cell death was determined by evaluating propidium iodide fluorescence. Each value is the mean \pm SEM of five independent experiments, including 30-45 cells. *: $\mathrm{p}<0.05$ versus control $(\mathrm{Ctl})$ cells; $\ddagger$ : $\mathrm{p}<0.05$ versus Dox.

Fig. 3: Cyclosporin A was able to prevent doxorubicin-induced mPTP opening without altering ROS production.

A: cardiomyocytes were cultured for 18 hours in the presence of increasing concentrations of doxorubicin (Dox), and then loaded with $1 \mu \mathrm{M}$ calcein-AM supplemented with $1 \mathrm{mM} \mathrm{CoCl} 2$. At the end of the incubation period, mPTP opening was evaluated by measuring calcein fluorescence.

B-H: cardiomyocytes were pretreated with cyclosporin A $(\mathrm{CsA}, 1 \mu \mathrm{M})$ and then cultured for 18 hours in the presence of $20 \mu \mathrm{M}$ Dox. B: cells were loaded with $1 \mu \mathrm{M}$ calcein-AM supplemented with $1 \mathrm{mM} \mathrm{CoCl}{ }_{2}$ and $\mathrm{mPTP}$ opening was evaluated by measuring calcein fluorescence. C: cells were loaded with $5 \mu \mathrm{M}$ DCF-DA or $1 \mu \mathrm{M}$ MitoSOX and ROS production was evaluated by measuring DCF and MitoSOX fluorescence. D: cells were loaded with $5 \mu \mathrm{M}$ fura-2-AM, were excited at $360 \mathrm{~nm}$ and $380 \mathrm{~nm}$ and the resulting fluorescence was measured at $510 \mathrm{~nm}$. E and F: cell shortening (E) and maximal velocities of contraction and relaxation (F) were measured in $1 \mathrm{~Hz}$ paced cells. G: Typical examples of cardiomyocyte contractions without or with $20 \mu \mathrm{M}$ Dox or $20 \mu \mathrm{M}$ Dox $+1 \mu \mathrm{M}$ CsA.

$\mathrm{H}$ : cells were loaded with propidium iodide and cell death was determined by evaluating propidium iodide fluorescence.

Each value is the mean \pm SEM of five independent experiments including 30-45 cells. *: $\mathrm{p}<0.05$ versus control $(\mathrm{Ctl})$ cells; $¥: \mathrm{p}<0.05$ versus Dox.

Fig. 4: Doxorubicin-induced contractile dysfunction was prevented by TSPO ligands.

$\mathrm{A}$ and B: cardiomyocytes were pre-treated with increasing concentrations of 4'chlorodiazepam (CDZ) or TRO40303 (TRO) and cultured for 18 hours in the presence of 
doxorubicin (Dox, $20 \mu \mathrm{M}$ ). Then cell shortening (A) and maximal velocities of contraction and relaxation (B) were measured in $1 \mathrm{~Hz}$ paced cells.

$\mathrm{C}$ and D: typical examples of cardiomyocyte contractions without or with Dox (20 $\mu \mathrm{M})$, Dox $+\operatorname{CDZ}(1 \mu \mathrm{M})$ or Dox + TRO $(3 \mu \mathrm{M})$ treatments.

Fig. 5: Doxorubicin-induced cell death, mPTP opening and ROS production were prevented by TSPO ligands.

A and B: cardiomyocytes pre-treated with increasing concentrations of 4'-chlorodiazepam (CDZ) or TRO40303 (TRO) and cultured for 18 hours in the presence of doxorubicin (Dox, $20 \mu \mathrm{M})$. At the end of the incubation period, cells were loaded with $1 \mu \mathrm{M}$ calcein-AM supplemented with $1 \mathrm{mM} \mathrm{CoCl}_{2}$ (A) or $5 \mu \mathrm{M}$ propidium iodide (B), and mPTP opening (A) and cell death (B) were evaluated by measuring calcein and propidium iodide fluorescence, respectively

$\mathrm{C}$ : cardiomyocytes were pre-treated with either $1 \mu \mathrm{M} \mathrm{CDZ}$ or $3 \mu \mathrm{M}$ TRO and cultured for 18 hours in the presence of $20 \mu \mathrm{M}$ Dox. Then, cells were loaded with $5 \mu \mathrm{M}$ fura-2-AM, were excited at $360 \mathrm{~nm}$ and $380 \mathrm{~nm}$, and the resulting fluorescence was measured at $510 \mathrm{~nm}$.

D: cardiomyocytes were pre-treated with either $1 \mu \mathrm{M} \mathrm{CDZ}$ or $3 \mu \mathrm{M}$ TRO and cultured for 18 hours in the presence of $20 \mu \mathrm{M}$ Dox. Then, cardiomyocytes were loaded with $5 \mu \mathrm{M}$ DCFDA or $1 \mu \mathrm{M}$ MitoSOX and ROS production was determined by evaluating DCF and MitoSOX fluorescence.

Each value is the mean \pm SEM of five independent experiments including 30-45 cells. *: $\mathrm{p}<0.05$ versus control $(\mathrm{Ctl})$ cells; $\ddagger$ : $\mathrm{p}<0.05$ versus Dox.

Fig. 6: Comparison of the effects of cyclosporin A and of the TSPO ligand, TRO40303 on doxorubicin-induced mPTP opening, ROS production and contractile dysfunction in cardiomyocytes isolated from wild type and CypD KO mice.

A: cardiomyocytes pre-treated with $3 \mu \mathrm{M}$ TRO40303 (TRO) or $1 \mu \mathrm{M}$ cyclosporin A (CsA) and cultured for 18 hours in the presence of doxorubicin (Dox, $20 \mu \mathrm{M}$ ). At the end of the incubation period, cells were loaded with $1 \mu \mathrm{M}$ calcein-AM supplemented with $1 \mathrm{mM} \mathrm{CoCl} 2$ and mPTP opening was evaluated by measuring calcein fluorescence.

B: cardiomyocytes were pre-treated with either $3 \mu \mathrm{M}$ TRO or $1 \mu \mathrm{M}$ CsA and cultured for 18 hours in the presence of $20 \mu \mathrm{M}$ Dox. Then, cardiomyocytes were loaded with $1 \mu \mathrm{M}$ MitoSOX and ROS production was determined by evaluating MitoSOX fluorescence. 
C: cardiomyocytes were pre-treated with either $3 \mu \mathrm{M}$ TRO or $1 \mu \mathrm{M}$ CsA and cultured for 18 hours in the presence of $20 \mu \mathrm{M}$ Dox and then cell shortening was measured in $1 \mathrm{~Hz}$ paced cells.

Each value is the mean \pm SEM of five independent experiments including 30-45 cells. *: $\mathrm{p}<0.05$ versus respective control $(\mathrm{Ctl}) ; \ddagger: \mathrm{p}<0.05$ versus respective cells treated with Dox. 
A

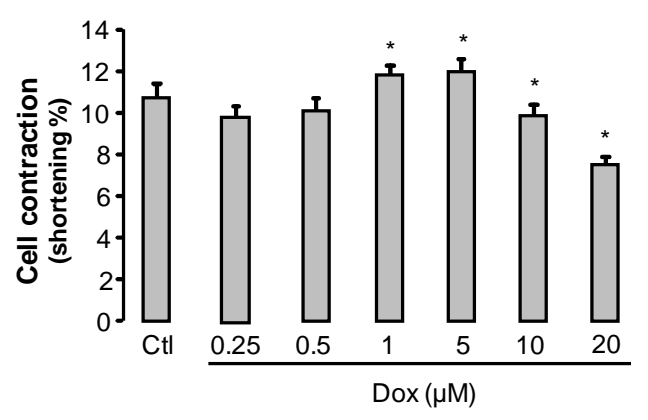

D

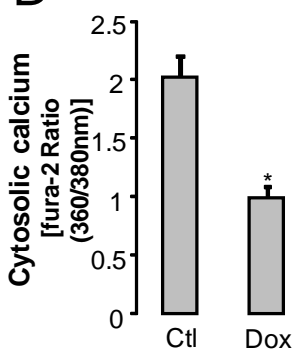

B

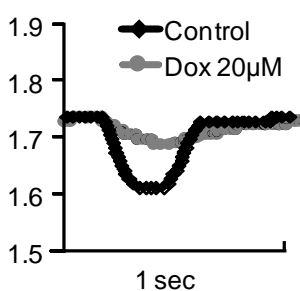

Fig 1

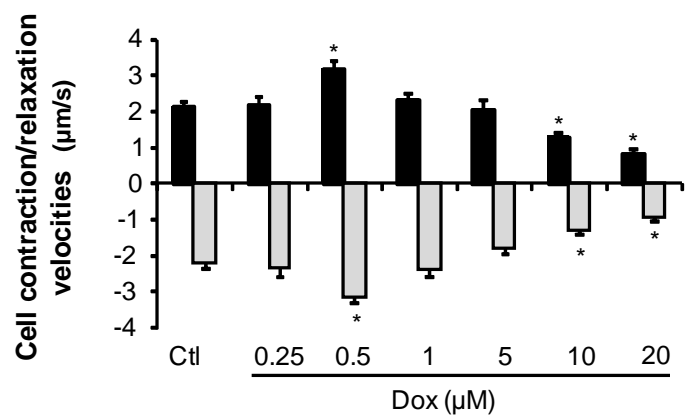

$E$ 
A B
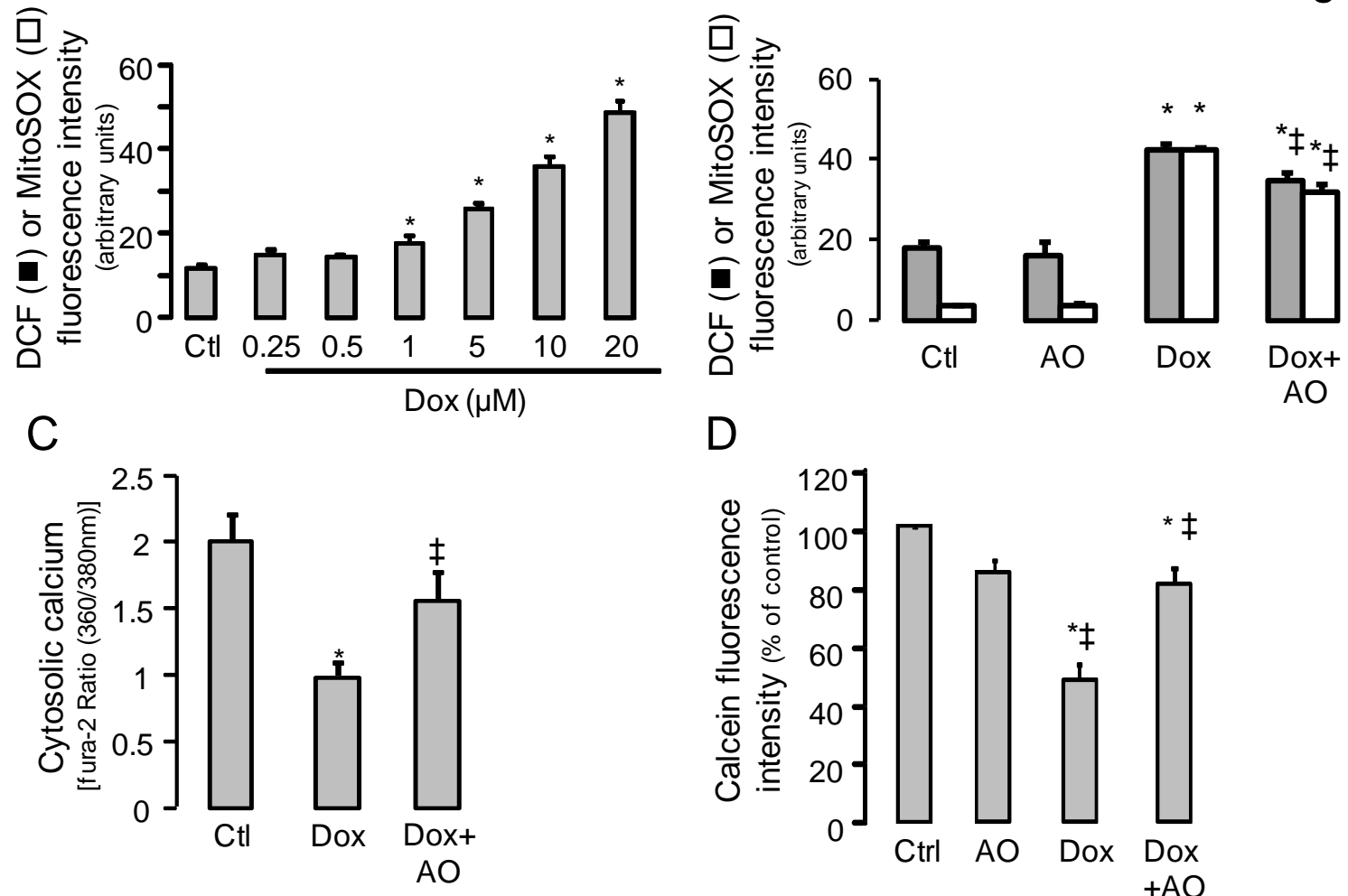

E
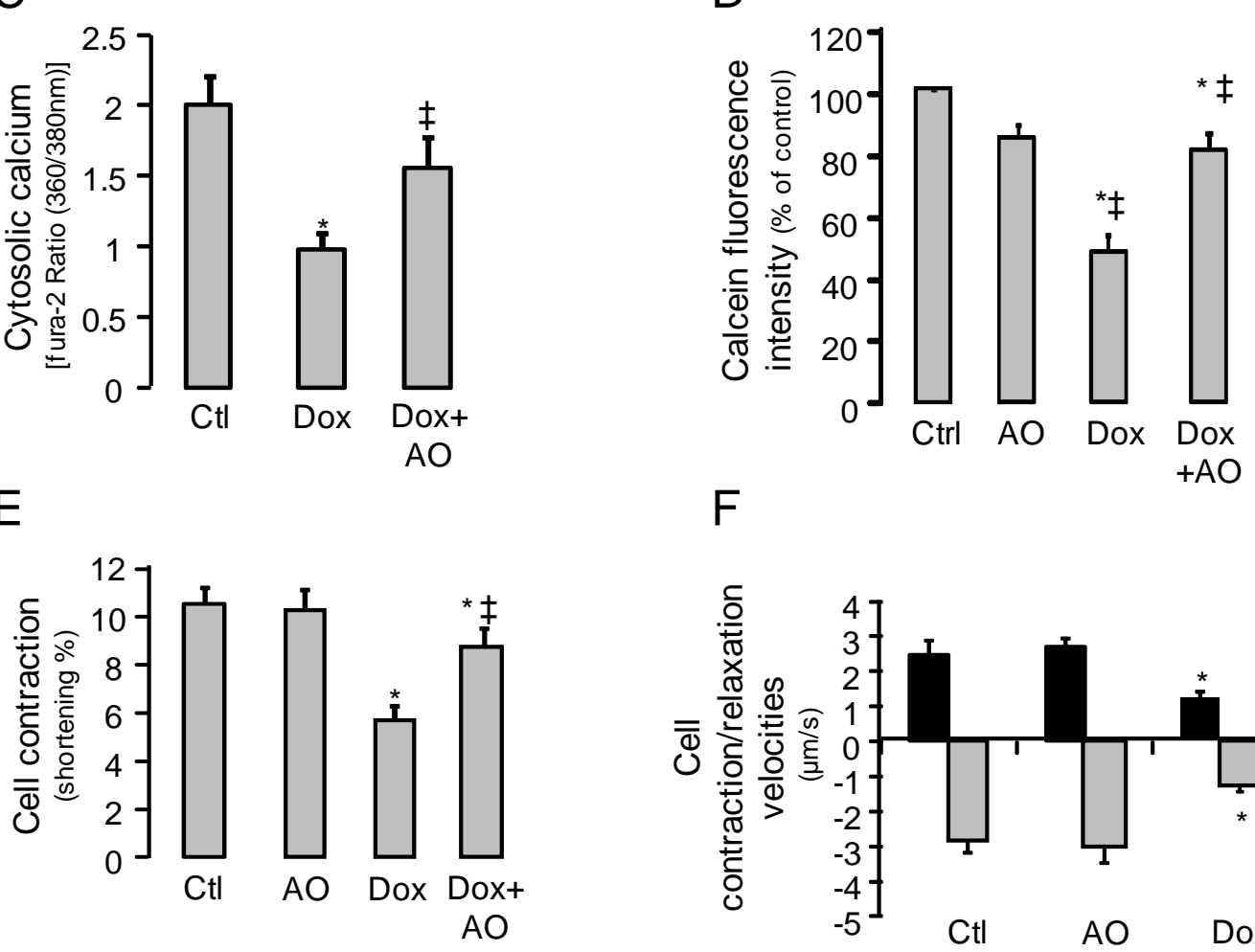

$\mathrm{F}$

Fig 2
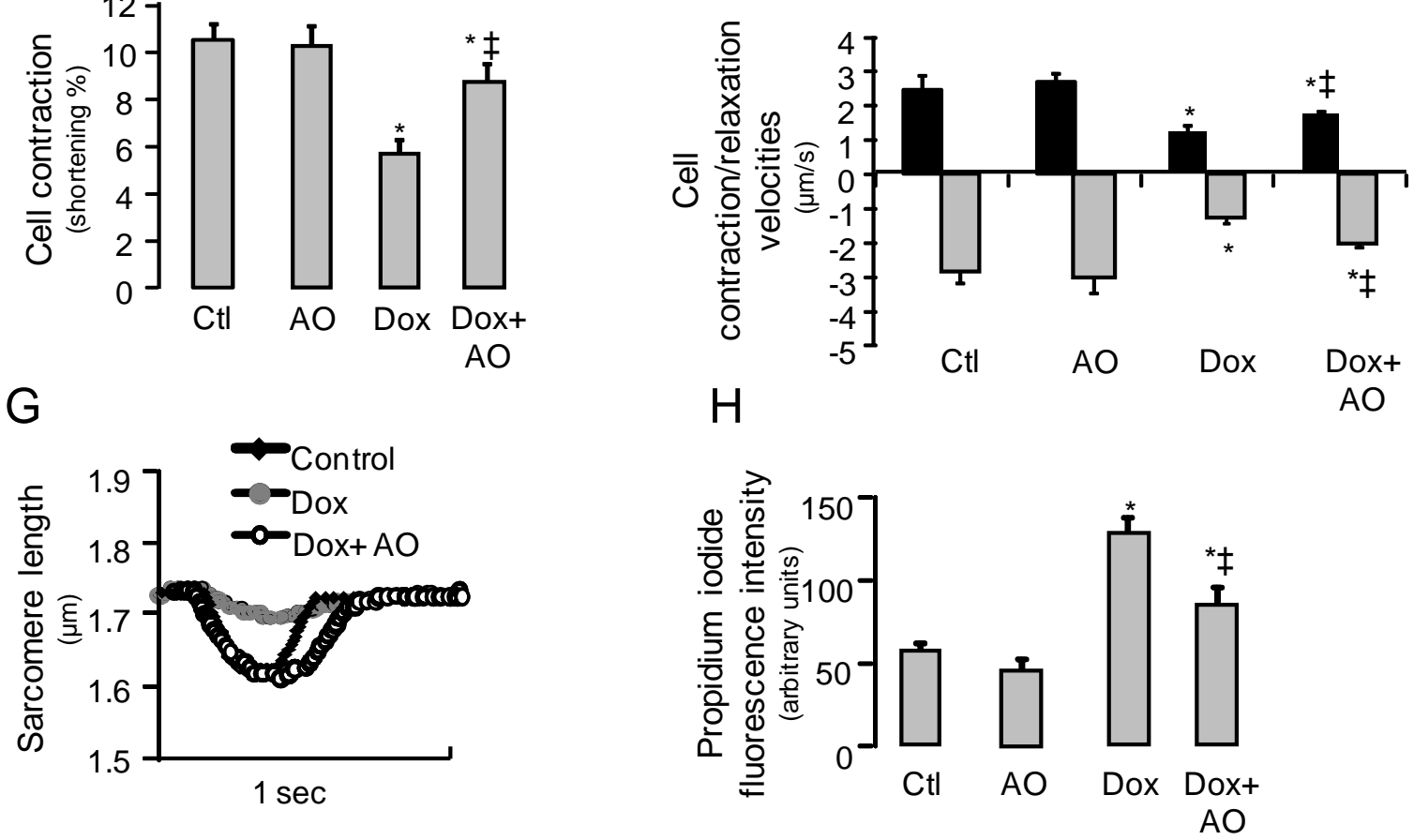

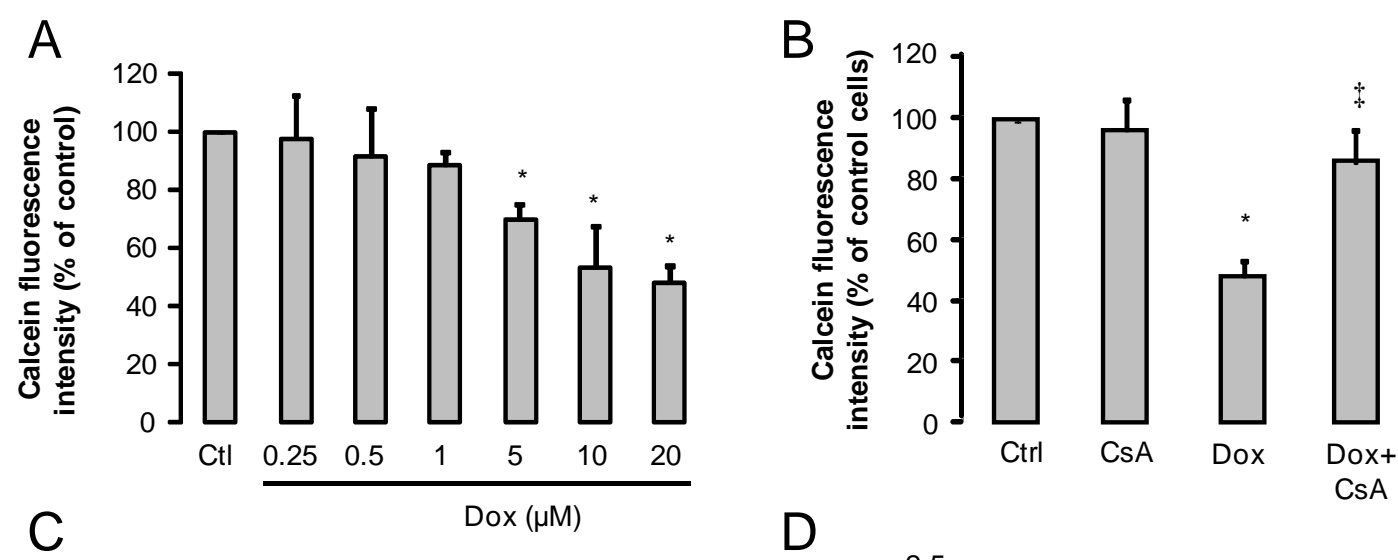

Fig 3
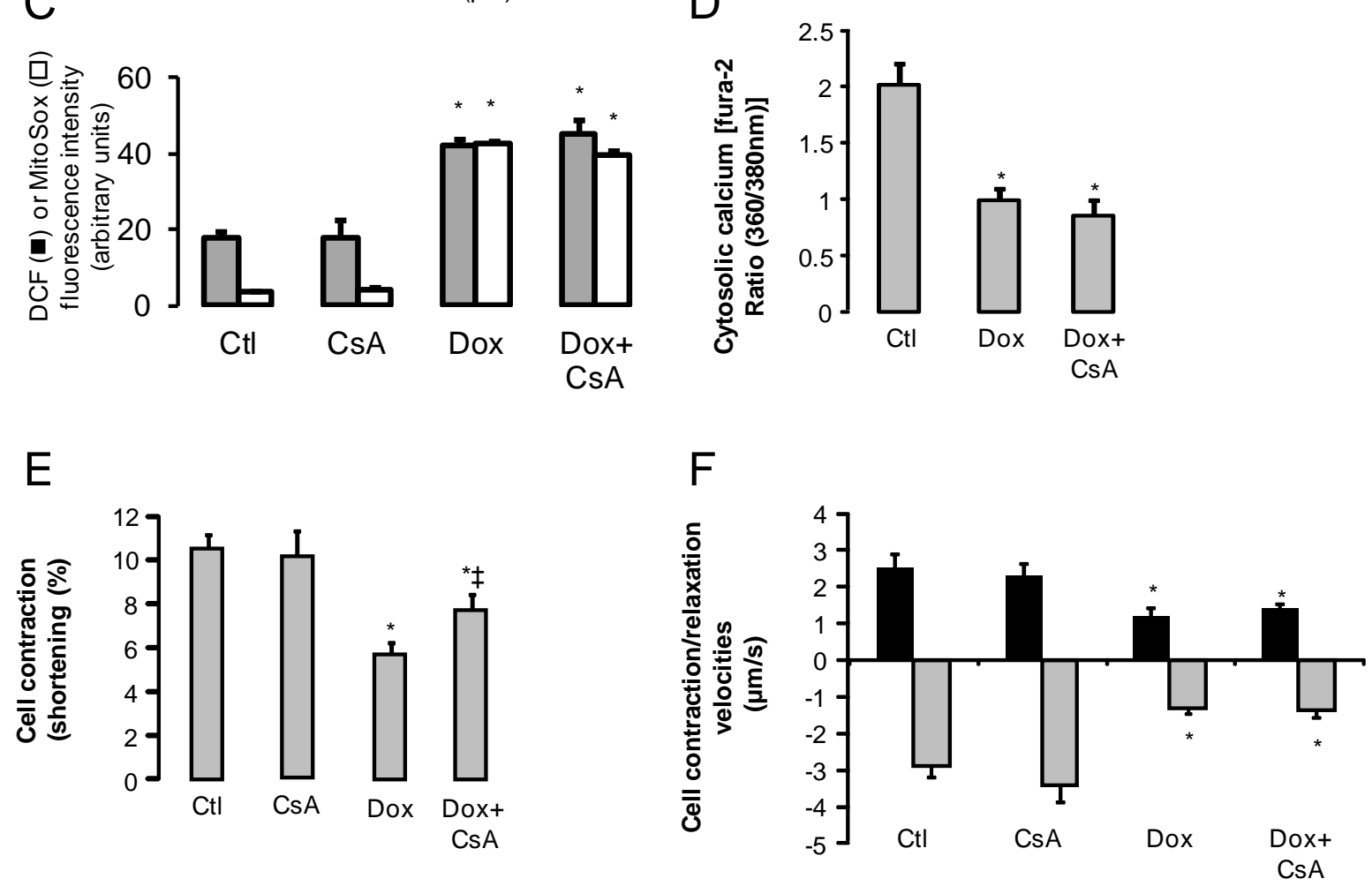

G

$\mathrm{H}$
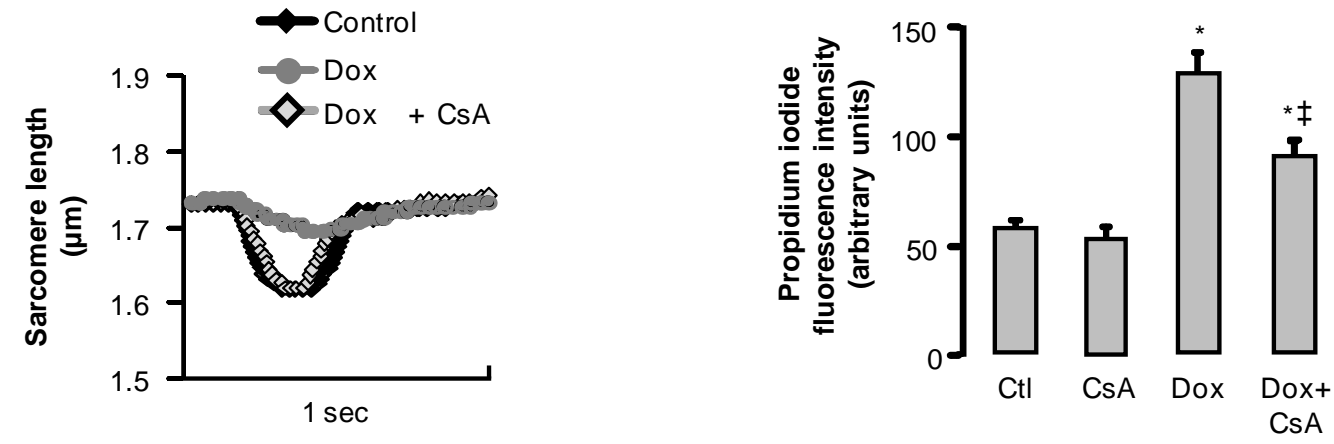
Fig 4

A
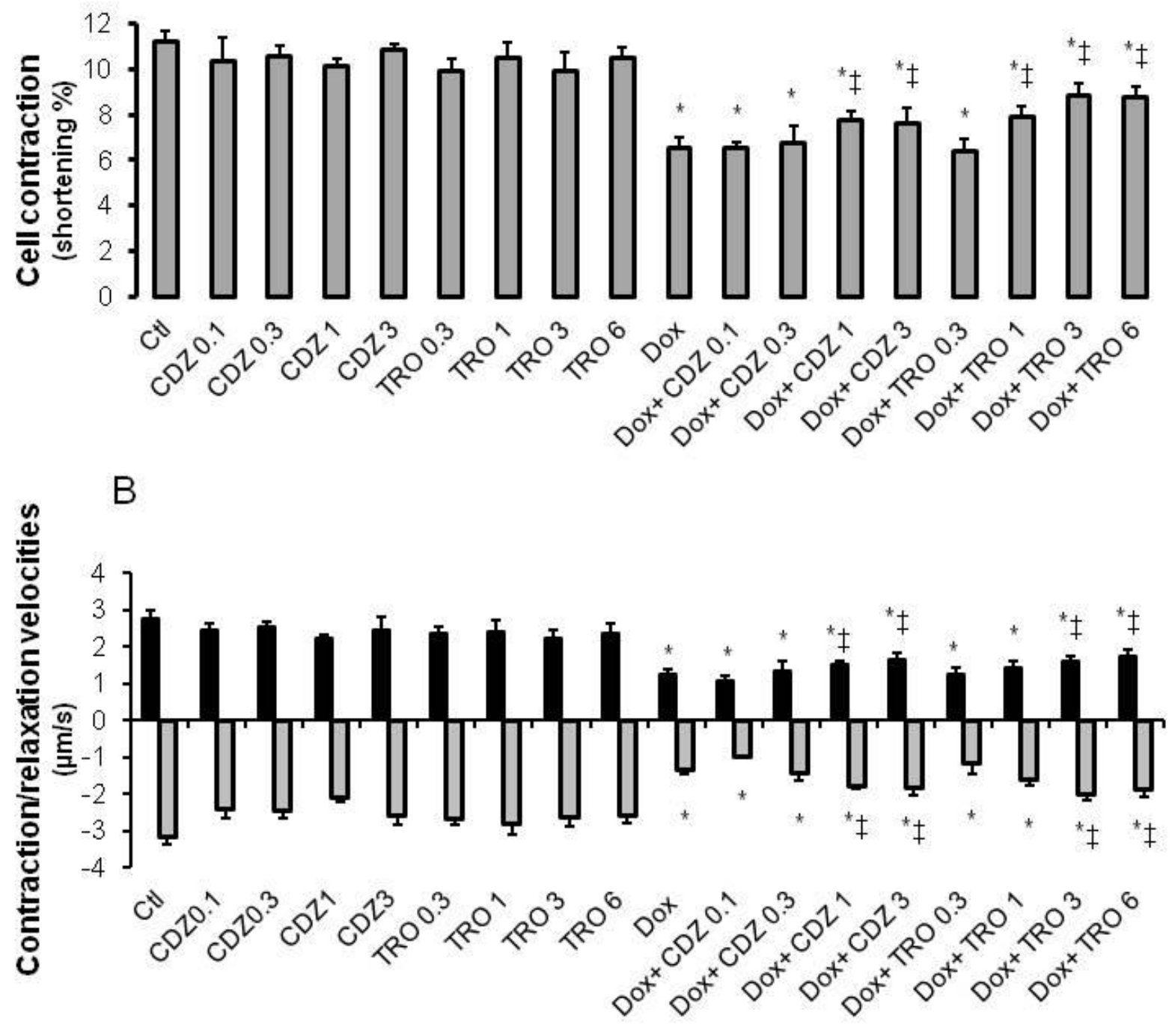

C

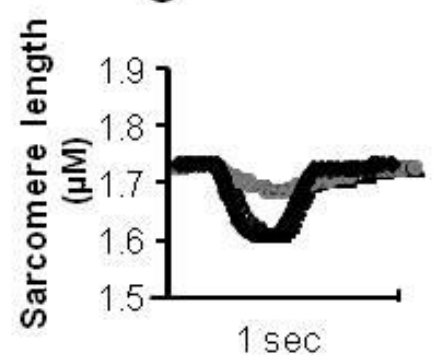

D

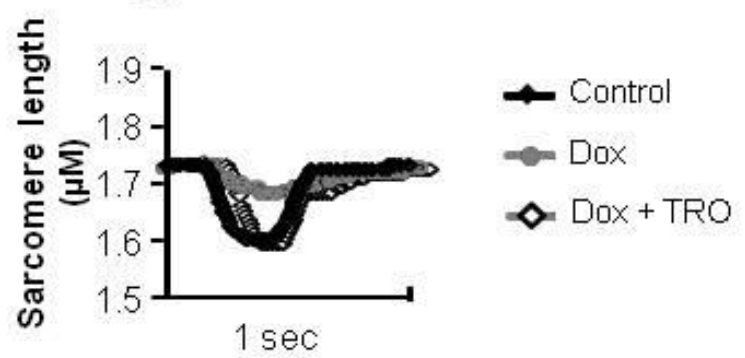



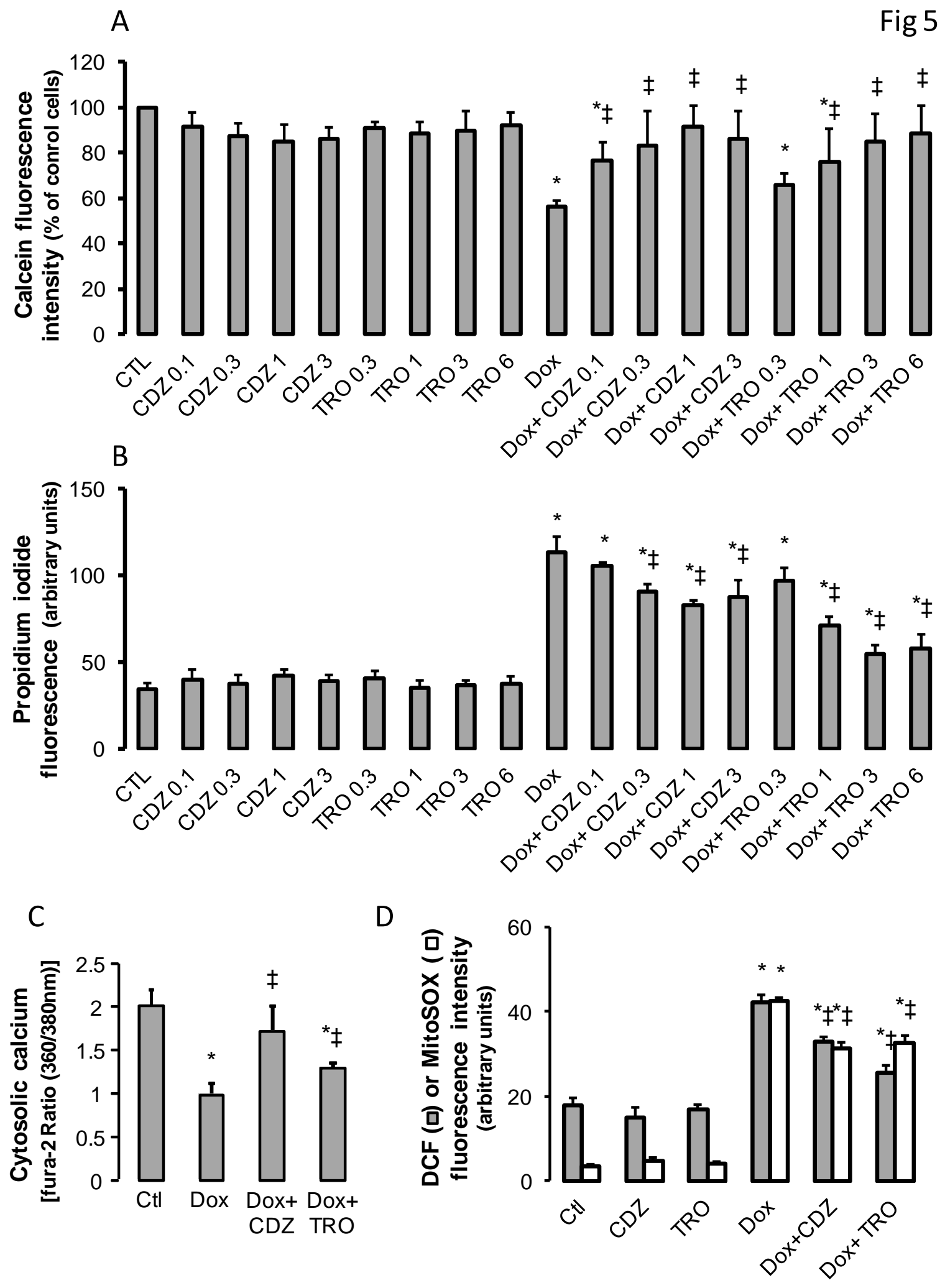


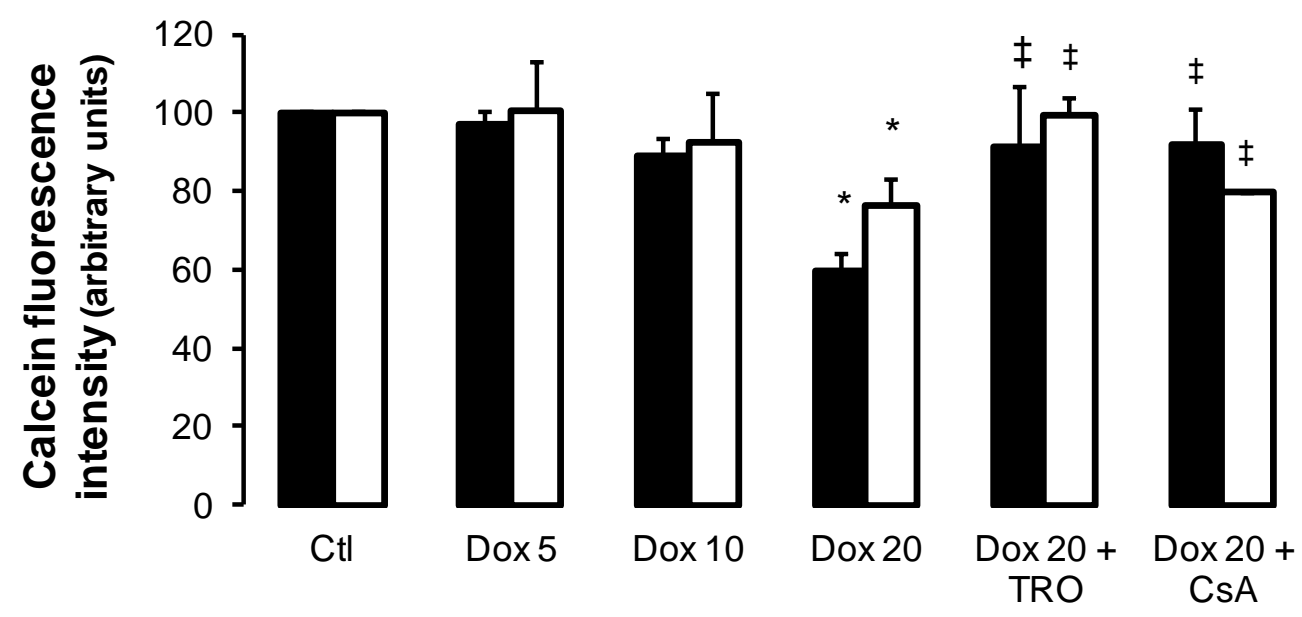

B
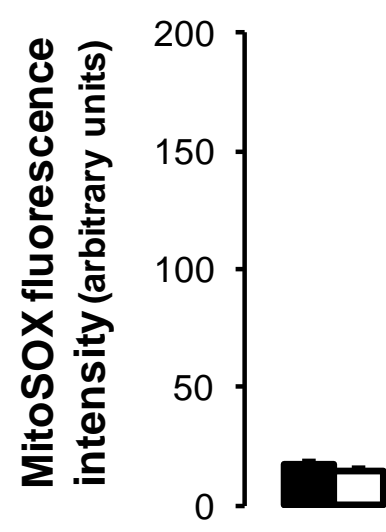

Ctl
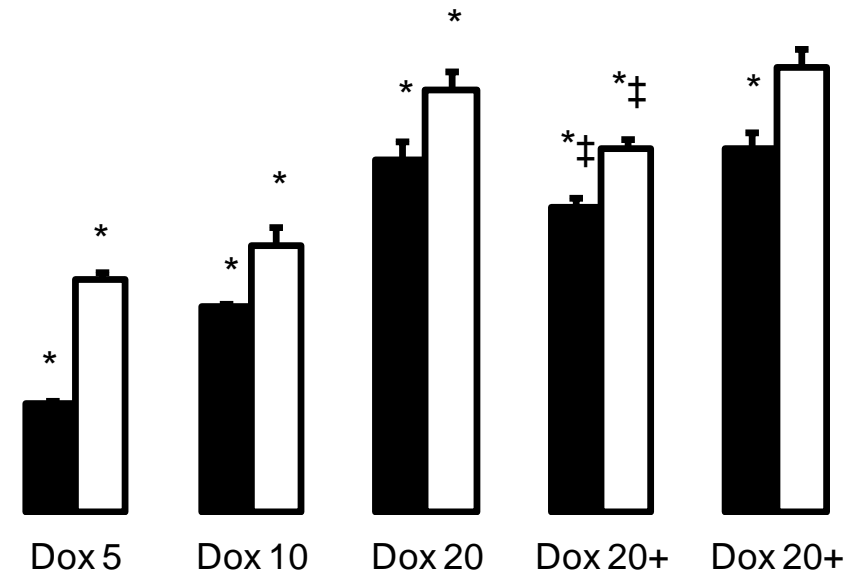

TRO CsA

C

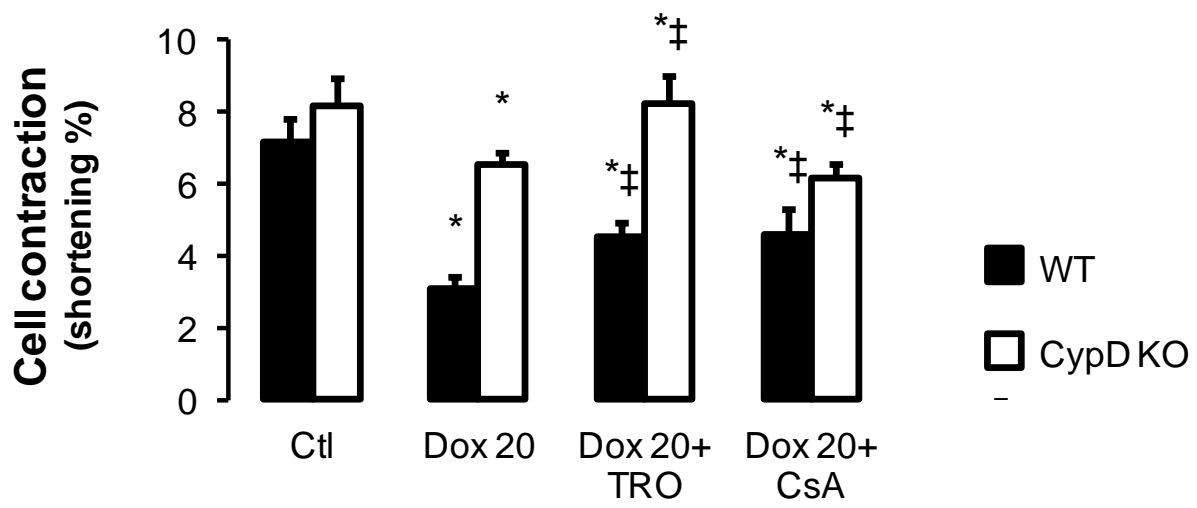


Table 1: sarcomere length

\begin{tabular}{lcc}
\hline \multicolumn{1}{c}{ Group } & $\mathbf{n}$ & sarcomere length $(\boldsymbol{\mu m})$ \\
\hline Control & & \\
CDZ & 34 & $1.68 \pm 0.01$ \\
TRO40303 & 11 & $1.70 \pm 0.01$ \\
Cyclosporin A & 16 & $1.73 \pm 0.04$ \\
Antioxidants & 14 & $1.70 \pm 0.02$ \\
Doxorubicin & 10 & $1.73 \pm 0.03$ \\
Doxorubicin + CDZ & 30 & $1.70 \pm 0.02$ \\
Doxorubicin + TRO40303 & 11 & $1.70 \pm 0.02$ \\
Doxorubicin + Cyclosporin A & 20 & $1.71 \pm 0.02$ \\
Doxorubicin + Antioxidants & 11 & $1.71 \pm 0.02$ \\
& 15 & $1.70 \pm 0.03$ \\
\hline
\end{tabular}

Effect on sarcomere length of 4 '-chlorodiazepam (CDZ, 1 $\mu \mathrm{M})$, TRO40303 $(3 \mu \mathrm{M})$, antioxidants (resveratrol $5 \mu \mathrm{M}$ and $\mathrm{N}$-acetylcystein $5 \mathrm{mM}$ ), Doxorubicin $(20 \mu \mathrm{M})$ or cyclosporin A $(1 \mu \mathrm{M})$ 